\title{
San Agustín y la cultura occidental
}

\section{Introducción}

En opinión de Agostino Trapé, "San Agustín es el más grande de los Padres y uno de los genios más eminentes de la humanidad". Juicio compartido también por R. Sierra Bravo cuando escribe: "es el más grande de los Padres de la Iglesia y uno de los pensadores más destacados de todos los tiempos". Y en modo alguno exageran estos autores cuando hacen tales afirmaciones. La influencia de San Agustín (354-430) en la cultura occidental puede se comparada con facilidad con la ejercida por el mismo Aristóteles. Más aún, la cultura occidental - como síntesis de la tradición cultural grecoromana y la tradición cultural judeocristiana - comienza a adquirir sus perfiles más propios en las elaboraciones (teológicas, filosóficas, místicas, poéticas y doctrinales) de este gran pensador de Hipona. Su obra teológica es la que mejor refleja la densidad y amplitud de sus reflexiones. El impacto y trascendencia histórica de la misma no hace sino confirmar su hondura teológica.

La obra teológica de San Agustín es de las más vastas que haya podido producir una sola inteligencia. Entre libros, cartas y tratados su producción teológica sobrepasa los 400 escritos. Asimismo, estos escritos -aparte de las diversas ediciones y traducciones de que han sido objeto- han despertado - y despiertan- el interés de teólogos y filósofos, que siguen encontrando en ellos motivos de reflexión y de profundización en sus campos de saber respectivos. En lo que toca al impacto y transcendencia histórica de la obra de nuestro autor, es más que reconocida su incidencia en la evolución del dogma y la eclesiología. Es así que ha merecido el respeto y la admiración de diferentes papas, desde Celestino I, pasando por Bonifacio II y Juan II, hasta León XIII, Pío XI y Pablo VI. Asimismo, "los Concilios

* Director del CIDAI. Maestro por la FLACSO-México 
- el de Orange, sobre el pecado original y la gracia; el de Trento, sobre la justificación; el Vaticano I, sobre las relaciones entre razón y fe, y el Vaticano II, sobre el misterio de la Iglesia, la revelación y el misterio del hombre - han recurrido abundantemente, sobre todo el primero, a su doctrina, mostrando así que no era de Agustín sino de la Iglesia, la cual, en consecuencia, la reconocía como propia".

Todo lo anterior hace interesante introducirse en el pensamiento teológico del Obispo de Hipona. Lo cual ciertamente no es fácil, dada la diversidad de problemas tratados por este autor en el conjunto de su obra. Hay, sin embargo, algunos motivos que se pueden estimar como claves y significativos en su pensamiento. Estos motivos se pueden agrupar en tres tópicos: a) las controversias con los maniqueístas, los donatistas, y los pelagianos; b) la temática de las virtudes teologales; y c) la problemática eclesiológica.

Nuestro propósito es abordar someramente cada uno de esos tópicos. No nos cabe la menor duda de que estamos dejando de lado aspectos esenciales del pensamiento de San Agustín. Pero tampoco dudamos que los temas elegidos son lo suficientemente importantes como para merecer atención. Más aún, el mero hecho de ser elementos presentes en el pensamiento de San Agustín garantiza el enriquecimiento mental de quien hace el esfuerzo por comprenderlos. En más de una ocasión Ignacio Ellacuría sostuvo que los grandes autores son grandes porque, ante todo, enseñan a pensar; incluso más - decía él- hay que acercarse a los grandes autores, estemos o no de acuerdo con los contenidos que proponen, para aprender a pensar. Esta es una buena razón para acercarse al pensamiento de San Agustín.

\section{Las controversias de San Agustín}

San Agustín elaboró buena parte de su obra teológica en confrontación con otras perspectivas teológicas y filosóficas de su tiempo. En concreto, se enfrentó con los maniqueos, los donatistas y los pelagianos. De estas controversias fueron surgiendo contenidos teológicos originales, que han constituido un aporte fundamental al desarrollo de la teología occidental.

\subsection{Contra los maniqueos}

Una obra clave para comprender esta controversia agustiniana lo constituye la obra: De las costumbres de la Iglesia católica y de las costumbres de los maniqueos (De moribus ecclesiae catholicae et de moribus manichaeorum), cuyo propósito es "quitar la máscara de virtud con que se cubrían los santos o elegidos maniqueos, para que aparezca en toda su desnudez la hipócrita austeridad, junto con la verdad de su increíble y universal corrupción". Pero San Agustín avanza mucho más en su crítica a la "podredumbre" maniquea (T. Prieto). Nuestro autor "opone a ella la verdadera santidad 
de las costumbres cristianas en su doctrina y en su práctica; pues así se ve mejor, a la luz de los resplandores y atractivos irresistibles de la heroica santidad de la Iglesia católica, la fealdad y repugnancia de la tan decantada santidad de las costumbres maniqueas".

La polémica se dirige, pues, contra las costumbres maniqueas, a las que se oponen las costumbres cristianas. Es decir, se trata de una polémica fundamentalmente ético-moral. "Los maniqueos —dice San Agustín- usan principalmente dos artificios para seducir a los sencillos y pasar ante ellos como maestros: uno la censura de las Escrituras, que entienden o pretenden entender muy mal; y el otro, la ficción de una vida pura y de continencia admirable. Yo he resuelto, en consecuencia, tratar de la vida y costumbres de la Iglesia católica; y comprenderá quien lo leyere qué fácil es simular la virtud y qué difícil poseerla con perfección". Ahora bien, ¿quiénes son los maniqueos y cuál es su doctrina?

Los maniqueos son los que defienden y propagan la doctrina de Mani (nacido en Babilonia el año 215 o 216) en tiempos de San Agustín. Los discípulos de Mani forman una secta caracterizada por la "austeridad moral", la "luz" que prometen dar acerca de los "secretos de la vida y la naturaleza" y la "esplendidez de su culto". Esta "vida moral" (y "sabia") se alimenta de elementos budistas, cristianos zoroástricos y gnósticos, que han sido sistematizados, transformados y deformados.

El principio de esta sistematización es un agnosticismo de tipo dualista (T. Prieto). "En la elaboración que éste sufrió por obra de Mani queda como fundamento la antítesis entre los dos principios supremos transformados en luz y tinieblas; y no sólo el principio de la luz, sino también el de las tinieblas, se desarrollan en una serie de eones, y de su mezcla se ha originado el mundo. Existe una región de la luz y otra región de las tinieblas o de la materia; y en el hombre, lo mismo que en el universo y en cada uno de sus elementos, se da una mezcla de los dos, luz y tinieblas".

Por consiguiente, hay que "dar libertad a las partículas de luz cautivas en la materia y tinieblas, con el fin de que retornen a su propio reino, que es el cielo, de donde salieron". El camino de esa liberación de la materia es señalado por Jesús. Los "elegidos" tienen que regirse por la "regla de santidad, cuyo símbolo son tres sellos: el de la boca, el de la mano y el del seno". Es en estos tres sellos que fundamenta la ética maniquea: "En virtud del sello de la boca está prohibido a los discípulos de Mani introducir en la boca nada impuro, así como tampoco salir de ella... El sello de la mano prohibe en absoluto a los sectarios de Mani matar y hacer todo lo que tanga algo de semejante con esta acción... El sello del seno es más importante que los demás, porque trata de oponerse a la propagación del mal”. 
Los maniqueos propugnaban por una moral radicalmente austera. Tan austera que "sólo obligaba con todo su rigor a los santos y a los elegidos, porque constituía un ideal de santidad que la masa no podía realizar". Por tanto, sólo los santos y los elegidos estaban en camino - $\mathrm{e}$ incluso participaban ya- del reino de la luz. Con la muerte, éstos tendrían garantizada "la entrada inmediata en el reino de la luz o paraíso". Es decir, con la muerte los santos y elegidos - los buenos - se alejarán definitivamente del mundo de los pecadores, cuya suerte es "el infierno, con sus torturas eternas y sin esperanza". Este proceso apunta últimamente hacia "la separación definitiva de los buenos y los malos, o sea de la luz y las tinieblas", que se "hará esperar un número incontable de siglos, para el retorno a su origen de los eones luminosos, cautivos en el universo de la materia".

Este será el momento final de la evolución del universo: se liberará totalmente el principio de la luz de las ataduras de las tinieblas. "Al fin de los tiempos... un incendio universal se cebará sobre la tierra para purificarla y juzgarla. Con este acto final, las últimas partículas de luz todavía prisioneras de la materia serán puestas en libertad y subirán al cielo, mientras que la materia quedará informe y sin movimiento. Sobre el universo purificado reinará únicamente el principio bueno, sin temer invasión alguna de su contrario por toda la eternidad".

Esta visión maniquea de la realidad encuentra en San Agustín una serie de críticas importantes. Ante todo, nuestro autor se esfuerza por determinar la índole propia de la ética cristiana. Si la ética maniquea es una ética gnóstico-dualista (y de secta), la ética cristiana - nos dice San Agustínse fundamenta en Dios, expresión radical del sumo bien. Ahora bien, Dios - como sumo bien - se ha donado al hombre en cuerpo y alma: "El sumo bien del hombre es el que a la vez lo es del cuerpo y lo es del alma". Sin embargo, el hombre responde a esta donación de Dios esencialmente desde el alma, "única capaz de la virtud" y capaz, asimismo, de elevar la dignidad y perfección del cuerpo.

Es justamente la virtud la que hace al alma más perfecta; una virtud que se adquiere "siguiendo a Dios". Es este seguimiento el que, en definitiva, hace de la vida humana una "vida feliz". La virtud es, para el Obispo de Hipona, "la perfección del alma". Esta perfección se logra en el seguimiento radical de Dios: "Este es el fin de la dirección y referencia de todos nuestros pensamientos. Dios es para nosotros la suma de todos los bienes, es nuestro sumo bien. Ni debemos quedarnos más acá ni ir más allá: lo primero es peligroso, y lo segundo, la nada".

El Dios de San Agustín es un Dios absolutamente bueno. Se trata de un único Dios que se caracteriza por ser la expresión del sumo bien. Desde aquí nuestro autor lanza una severa crítica a las concepciones maniqueas. 
"Con vosotros - les dice- no se puede hablar de un Dios sin restricciones, porque distinguís dos, uno malo y otro bueno. Y cuando decís que adoráis y se debe adorar al Dios que hizo el mundo, pero no el que ensalza la autoridad del Viejo Testamento, os cegáis descaradamente en la mala interpretación de los pensamientos y palabras que hemos recibido tan llenos de verdad y salud".

Al ser Dios -expresión del sumo bien- el creador absoluto de todo lo existente, lo es también del mal. Es decir, "el mal procede del bien" (San Agustín). "Sin el bien no podría existir el mal. El bien que carece de todo mal es un bien absoluto; por el contrario, aquel al que está adherido el mal es un bien comupto o corruptible; y donde no existe el bien no es posible mal alguno".

Más severa aún es la crítica que apunta San Agustín en el siguiente texto: "No entendemos como vosotros - les dice a los maniqueos- la Ley y los Profetas. Abandonad el error: el Dios de nuestro culto no es un Dios penitente, ni envidioso, ni pobre, ni cruel, ni sanguinario, ni vicioso, ni que tiene su domino reducido a una pequeña parte de la tierra. Sólo contra estas niñerías son vuestras largas y aceradas críticas; no nos llegan; son pensamientos de viejas o de niños lo que combatís con estilo tanto más ridículo cuanto más enérgico y vehemente. Quienes, seducidos por vosotros, pasan a vuestras filas, no condenan nuestra doctrina, sino demuestran que la ignoran totalmente".

En definitiva, el dualismo gnóstico de los maniqueos les lleva a una conceptuación también dualista de Dios. El Dios bueno se entregaría a los "puros" y "santos", es decir, a los elegidos, mientras que el Dios malo se impondría entre los pecadores. Ese dualismo gnóstico no puede menos que desembocar un una ética de la pureza de tipo sectaria, sólo reservada a una minoría de privilegiados. Estamos, pues, ante un racionalismo fácil (J. Vives) - que pretende separar nítidamente el bien y el mal, lo puro y lo impuro- que será condenado radicalmente por San Agustín. El Dios experienciado -más que reflexionado- por el Obispo de Hipona es un Dios radicalmente bueno; es decir, un Dios que quiere la felicidad total del hombre, en cuerpo y alma. Un Dios que a través de Jesucristo y su Espíritu se une a los hombres: "La santidad nos une a Él. Totalmente penetrados del espíritu de la santidad, nos abrasamos en la plenitud y perfección de la caridad, que es la única que causa la unión y la semejanza con Dios". Estamos, en consecuencia, ante un Dios que quiere la salvación total de la humanidad, y no la salvación de unos cuantos sectarios que se sienten elegidos. De un Dios que es esencialmente bueno -es decir, que es el sumo bien- no pueden esperarse divisiones tan tajantes y nítidas entre los buenos y los malos -entre los santos y los pecadores-. 
Sí que hay una santidad que es bien vista por San Agustín: la santidad que nace del "perfecto amor a Dios", es decir, "el amor que se conserva íntegro e incorruptible para sólo Dios". Es de aquí que San Agustín deriva las virtudes propias de la vida cristiana: la templanza, la fortaleza, la justicia y la prudencia, virtudes todas que están llamados a poseer todos aquellos que asuman como "un sagrado deber el amar a Dios". A esto están llamados todos los hombres de la tierra, incluso las "almas que vuelan a ras de tierra" y a las que se tiene que elevar de "lo humano a lo divino".

\subsection{Contra los donatistas}

Como señala el P. Congar, uno de los objetivos fundamentales de la teología de San Agustín es "responder a las cuestiones suscitadas por el donatismo". Para acercarse a esta polémica hay un escrito importante de San Agustín: De la unidad de la Iglesia (Epístola a los católicos contra los donatistas) (De unitate eclesiae (Ad catholicos epistola contra donatistas)). Pero, ¿quiénes son los donatistas y cuál es su doctrina?

Los donatistas son los seguidores de Donato, quien fue Obispo de Cartago desde el 313 hasta el 347. Con Donato - hace notar el P. Congar- "nació una Iglesia paralela, la 'Iglesia de los mártires', la Iglesia de los puros, que contaba con comunidades casi por todas partes, sobre todo en Numidia interior. Pero ya no se extendió más allá de África".

En el fondo, los donatistas desembocan en un cristianismo sectario. San Agustín opondrá a este sectarismo la universalidad y comunitariedad propias de la donación de Dios a los hombres. Es decir, San Agustín reivindicará la catolicidad de la revelación de Dios. "Agustín no cesa de mostrar que Dios ha querido una Iglesia 'toto orbe diffusa'. Y en este sentido aporta una treintena de textos de la Escritura. Desarrolla una teología de la catolicidad concebida como universal, teología que ya había formulado anteriormente en su crítica al maniqueísmo. La Iglesia es esencialmente la Catholica; no se es cristiano sino en la comunión con una unidad tan vasta como el mundo: estar en comunión con el mundo entero".

El motivo fundamental de la polémica es claro. Los donatistas sostienen que la Iglesia, "fundada por Cristo y fertilizada con su sangre, ha degenerado sustancialmente por las indignidades de algunos de sus miembros y ha desaparecido de sobre la faz de la tierra, quedando como único reducto la facción de Donato". San Agustín no acepta esto. Y lo hace en nombre de la universalidad y unidad de la Iglesia, es decir, en nombre de la catolicidad: "Se discute entre nosotros dónde está la Iglesia, entre nosotros o entre ellos. La cual ciertamente es una sola, denominada por nuestros antepasados con el nombre de católica, para demostrar con sólo el nombre que se halla diseminada por todo el mundo". Afirmar lo contrario es ir contra 
las mismas Escrituras: "las Santas Escrituras nos demuestran... cómo empezó la Iglesia por Jerusalén, se propagó luego a Judea y Samaria y de allí a todo el mundo, donde continúa creciendo, hasta que, finalmente, conquiste todas las gentes, donde aún no existe. Quien evangelizase otra cosa sea anatema". "Y evangeliza otra cosa todo el que afirma que ha perecido la Iglesia y que permanece sólo en el África con el partido de Donato. Por tanto, sea anatema. O demuéstremelo por las Santas Escrituras, y entonces no sea anatema".

Dicho de otra forma, "no les es permitido a éstos sospechar o afirmar lo que dicen: que todos los buenos han desaparecido del mundo, de tal modo que sólo existen ya entre los donatistas; porque van contra la terminante afirmación del Señor: el campo es este mundo; dejad que crezcan ambos hasta la recolección; la recolección es el fin del mundo".

Los donatistas se piensan los escogidos. Es decir, se sienten los limpios y "puros". San Agustín se enfrenta críticamente a esta pretensión donatista. "No se cansa de citar y explicar los textos evangélicos que contienen la idea de una Iglesia mezclada, eclesial mixta (....). La separación de buenos y malos no es corporal aquí abajo: en este plano están todos mezclados". En este sentido, la separación entre buenos y malos al interior de la Iglesia no es tan nítida como parecen creer los seguidores de Donato. En la iglesia verdadera existen malos mezclados con buenos (San Agustín). "Poseemos incontables testimonios sobre la mezcla de los malos con los buenos en la comunión de los mismos sacramentos (...), sobre el escaso número de los buenos comparados con los muchísimos malos, a la vez que de la gran multitud de buenos si se los considera aparte, (pero) ninguna mezcla con los malos puede aterrar a los buenos, de suerte que quisieran como romper las redes y separarse de la unidad, a fin de no tener que soportar en la comunión de los sacramentos a los que no pertenecen al reino de los cielos; puesto que les mantiene la esperanza de que cuando lleguen a la orilla, esto es, al fin de los siglos, se llevará a cabo la debida separación, no precisamente según el temerario criterio humano, sino según el justo juicio divino".

En definitiva, la separación entre buenos y malos -entre limpios y pecadores- es algo que sólo a Dios compete. Asimismo, es algo que habrá de dilucidarse —que habrá de dilucidar Dios-al final de los siglos; es decir, se trata de un acontecimiento escatológico (Y. Congar). Es hasta el final de los tiempos que la "Ecclesia quae futura est" - para la que vale la "fórmula paulina sobre la Iglesia sin mancha ni arruga"- se separará definitivamente de la "Ecclesia qualis nunc est" (Y. Congar). "Así sucederá en la terminación de los tiempos: vendrán los ángeles, y separando los malos de entre los justos, los arrojarán en un horno de fuego; allí será el llorar y el rechinar de dientes" 


\subsection{Contra los pelagianos}

Esta corriente constituye otro punto de confrontación en la obra de San Agustín. A la crítica y refutación de las tesis pelagianas dedica nuestro autor una buena cantidad de escritos, entre los que destaca: De la naturaleza y de la gracia (De natura et gratia) en el que responde al De natura de Pelagio (¿360-422?). En esta controversia lo que está en cuestión es el problema de las relaciones existentes entre gracia y naturaleza. ¿Cuál es la postura de los pelagianos al respecto y cuál es la postura de San Agustín?

Los pelagianos quieren reivindicar la autosuficiencia de la naturaleza humana con miras a la salvación, acentuando menos la primacía de Dios. En este punto, los discípulos de Pelagio son herederos de San Antonio, quien "realza más la bondad de la naturaleza humana que sus miserias, la actividad humana que la inspiración divina, la libertad y la responsabilidad de nuestros actos que las deficiencias de nuestra voluntad. Lo mismo es para San Antonio vivir conforme a la naturaleza que ser perfecto cristiano". Este humanismo de San Antonio se convierte en los pelagianos en un "humanismo naturalista, orgulloso y duro, que hubiera hecho imposible la creación de personalidad cristiana".

Enfrentados al problema de las relaciones gracia-naturaleza, la opción de los pelagianos es clara: su opción es por la naturaleza. Y, como indica V. Capánaga, esta opción no es ajena a los elementos farisaicos presentes en el pensamiento de Pelagio. Justamente por estos elementos, "no admitía una gracia interna dada al hombre para remedio de su debilidad. El hombre es justo por los dones naturales y la ley, a la cual considera como fuente universal de salvación". En lo que toca al problema de la justicia, la posición del fariseo es bien definida: "la justicia consiste en el minucioso cumplimiento de la ley con la esperanza de las recompensas temporales. El fariseo se gloría de sí mismo como artífice único de sus obras morales, y busca la alabanza humana en ellas con un orgullo repugnante, tantas veces fustigado por Cristo". Esta mentalidad fue asumida por Pelagio: "Pelagio, exagerando las fuerzas del libre albedrío y la suficiencia de la ley, forjó una espiritualidad de tipo farisaico".

La consecuencia más grave de estas tesis pelagianas es -como indica V. Capánaga - que se "anula completamente el dogma de la revelación y de la gracia. Con él -con Pelagio- el hombre vuelve a la paganía y al judaísmo, como si Jesucristo no hubiera venido al mundo para una mejora sustancial de relaciones con Dios y una nueva forma de existencia para la persona humana". La reacción de San Agustín en defensa de los fueros de la gracia no se hace esperar. El Obispo de Hipona se revela contra "tamaña deserción y desvarío" (V. Capánaga). 
San Agustín no acepta la negación de la gracia sostenida, en el fondo, por los pelagianos. El culto que éstos rinden al "libre albedrío" es inaceptable para aquél. Aceptar a Cristo - nos dice San Agustín- es aceptar el don de la gracia que Él libremente nos ha entregado. Es asumir la "consciencia de la debilidad humana, la incapacidad del libre albedrío para salvarse por sí mismo". Sólo quien acepta la intrínseca debilidad y finitud humana puede aceptar la gratuidad de Dios, expresada de modo pleno en Jesucristo. Porque el hombre no es autosuficiente es por lo que puede ser -y essalvado y justificado gratuitamente de Dios, a través de su Hijo: Christus sanat, Christus mundat, Christus iustificat, homo non iustificat (San Agustín). "Cristo no es sólo un héroe moral y maestro incomparable, sino el nuevo Sacerdote que con su divina sangre operó la purificación de la Humanidad, santificándola y uniéndola a Dios. Cristo es el que sana, Cristo el que limpia de las culpas, Cristo el que justifica; no son los hombres justificadores de sí mismos".

La tesis fundamental que San Agustín opone a los pelagianos en este punto dice lo siguiente: "de ningún modo pudo o puede haber justos sin la gracia justificante de Dios por Jesucristo, nuestro Señor, y este crucificado. La misma fe salvó a los justos antiguos y nos salva a nosotros, conviene a saber, la del Mediador entre Dios y los hombres, el Hombre Jesucristo; la fe en su sangre, la fe en su cruz, la fe en su muerte y resurrección. Luego teniendo nosotros el mismo espíritu de fe, también creemos, y por esto igualmente hablamos".

Digamos, para finalizar con este apartado, que nuestro autor no niega la naturaleza. El humanismo cristiano que orienta su quehacer vital -teológico y doctrinal - le lleva a reivindicar la realidad humana en su dimensión de "reverbero de maravillas y gloria de Dios" (V. Capánaga). Sin embargo, no se le oculta que la humanidad no es por naturaleza "enteramente sana y perfecta, sino enferma y débil y necesitada de un socorro celestial". No se hace justicia ni a Dios ni al hombre cuando éste es magnificado en su naturaleza, sino cuando se confiesa al Creador y Salvador y cuando se afirma la necesidad humana de salvación. Afirmar la grandeza de Dios no significa disminuir la naturaleza humana, sino poner de relieve el infinito amor que Dios siente por el hombre y que se manifiesta en "su misericordia y el misterio humildad, así como las mayores profundidades y riquezas de Cristo (que) se revelan no en su doctrina, sino en su redención".

\section{Las virtudes teologales: fe, esperanza y caridad}

Hemos reseñado los aspectos más sobresalientes de las controversias sostenidas entre San Agustín y las corrientes maniqueas, donatistas y pelagianas. En las mismas, el Obispo de Hipona va dejando plasmadas intuiciones 
teológicas que serán parte esencial de su pensamiento y que constituirán una parte importante de su herencia para la teología posterior. Estas intuiciones se expresan en las llamadas virtudes teologales: fe, esperanza y caridad, que vienen constituir los ejes en tomo a los cuales San Agustín organiza su reflexión teológica.

Una obra clave para acercarse a la problemática de las virtudes teologales -y en general al pensamiento teológico de San Agustín- es el Enquiridión o manual de la fe, de la esperanza y de la caridad (Enchiridion sive de fide, spe et caritate), obra que quiere responder a la siguiente pregunta - formulada al Obispo de Hipona por Lorenzo (Laurentio)- ¿ ¿cómo debe ser adorado Dios?

La respuesta de San Agustín es directa: "Dios debe ser adorado por la fe, por la esperanza y la caridad". Ahora bien -como él mismo reconoce-, dicha respuesta merece una ulterior explicación. Es decir, en el fondo se tiene que responder "qué es lo que principalmente debemos profesar, y qué, a causa de las herejías, especialmente evitar; hasta dónde puede llegar la razón en defensa de la religión, y en qué asuntos, que superan la razón, hemos de guiarnos sólo por la fe; cuál es el principio y complemento de la vida cristiana y cuál es la síntesis de toda su perfección, y cuál es el fundamento evidente y característico de la fe católica". Pero para responder a estas interrogantes hay que remitirse inexorablemente a las virtudes teologales. Como punto de partida, hay que saber con precisión "qué se debe creer, esperar y amar. He aquí las cosas que principalmente, o por mejor decir, las únicas que en la religión se han de abrazar. Quien las contradice o es en absoluto ajeno a Cristo o es un hereje".

a) La fe del creyente no se apoya en sí misma, sino que se sustenta en Cristo. O, dicho de otra forma, "el fundamento evidente y característico de la fe católica es Cristo, como escribió San Pablo a los Corintios: nadie puede poner otro fundamento sino el que está puesto, que es Jesucristo". Cuando el creyente se deja penetrar por esta fe en Cristo, es cuando "halla la inefable belleza, cuya plena visión constituye la plena felicidad".

Pero no basta sólo con aceptar que Cristo es el fundamento de mi fe. Tener fe es tener confianza plena en Dios y en su absoluta bondad. Es decir, supone aceptar "que la causa de todas las cosas creadas, celestes y terrenas, visibles e invisibles, no es otra que la bondad del Creador, Dios único y verdadero; y que no existe sustancia alguna que no sea Él mismo o creada por Él, y que es también trino: el Padre, el Hijo, engendrado por el Padre, y el Espíritu Santo, que procede de los dos, pero único y el mismo Espíritu del Padre y del Hijo". 
La fe, en este sentido, es una virtud teologal fundamental. La tradición teológica posterior a San Agustín hizo de la fe el núcleo central de la teología, que vino a convertirse en un intellectus fidei, es decir, en una aprehensión intelectual de la fe. Ciertamente que la teología es intellectus fidei. Pero, como ha sido defendido por la teología moderna, especialmente por J. Moltmann -inspirado por el Principio esperanza de E. Bloch-, la teología es también intellectus spei, es decir, aprehensión intelectual de la esperanza. Ya en San Agustín nos encontramos con que la fe no es independiente de la esperanza $y$, por consiguiente, con que la esperanza - al igual que la fe - es una virtud teologal fundamental. Es decir, desde San Agustín es legítimo pensar la teología no sólo como una intelección de la fe, sino también como una intelección de la esperanza.

b) La esperanza "no versa sino sobre cosas buenas y futuras y que se refieren a aquel de quien se afirma que posee la esperanza de ellas". "Acerca de la esperanza dice también el Apóstol: la esperanza que se ve, ya no es esperanza. Porque lo que uno ve, ¿cómo esperarlo? Pero si esperamos lo que no vemos, en paciencia esperamos. Luego cuando alguno cree que ha de poseer bienes futuros, no hace otra cosa que esperarlos". En este sentido, la espera confiada de lo futuro - como algo bueno- es una virtud teologal fundamental. Sin asumirla vitalmente, no se puede vivir una auténtica vida cristiana. Y la esperanza, así entendida, está estrechamente vinculada a la fe. Poseen una coincidencia fundamental: "la fe y la esperanza coinciden en que tanto el objeto de la una como el de la otra es invisible". Pero hay un vínculo más profundo: no se puede esperar confiadamente el futuro sin una honda fe en el señor del universo. Es decir, no se puede tener una esperanza auténtica - la esperanza contra toda esperanza - sin fe. $\mathrm{Y}$, a lo inversa: sin esperanza no puede haber una auténtica fe.

Fe y esperanza se alimentan recíprocamente. El intellectus fidei y el intellectus spei nos acercan intelectualmente a la realidad de Dios. Pero no basta con esto. Como ha recordado la Teología de la Liberación, al Dios de Jesús no se accede sólo y privilegiadamente por la fe y la esperanza. Para acceder al misterio del Padre hay que tener, ante todo, una actitud misericordiosa ante los condenados de la tierra, es decir, ante los pobres y oprimidos. Esta actitud de misericordia —que conlleva de suyo a una praxis de justicia - es strictu sensu caridad. Porque la caridad nos acerca a Dios $-y$, como dice San Agustín, es una forma de adoración que a Él sí le complace- es por lo que se convierte, al igual que la fe y la esperanza, en una virtud teologal fundamental. En cuanto tal, se convierte ¿puede y tiene que convertirse? en un momento de la teología. Y cuando la teología hace de la caridad el término formal de que 
quehacer teórico se convierte en intellectus caritate, en intellectus amoris (J. Sobrino). Al igual que desde San Agustín es legítimo pensar la teología como intellectus fidei y como intellectus spei, también es legítimo pensarla desde él como una intelección de la caridad (intellectus caritate).

c) La caridad consiste fundamentalmente en el compromiso radical por la felicidad del otro. Este compromiso tiene, en San Agustín, una dimensión de justicia bien concreta. Hace suyo el planteamiento de San Juan cuando dice: "Quién tuviere riquezas en este mundo y viere a su hermano padecer hambre y le cerrare sus entrañas, ¿cómo podrá habitar la caridad de Dios en él?". E inmediatamente comenta nuestro autor: "He aquí dónde comienza la caridad. Si aún no eres capaz de dar la vida por el hermano, sé, por lo menos, capaz de darle tus bienes. Penetre ya la caridad en tu corazón, de modo que no hagas el bien por jactancia, sino por la enjundia íntima de la misericordia, y te intereses por el que se encuentra necesitado". Poseer la virtud de la caridad es, pues, estar dispuestos a dar la vida por los hermanos, "como Él da la vida por nosotros". "Esta es la perfección de la caridad y la mayor perfección que puede en absoluto encontrarse".

Entre fe, esperanza y caridad existe una íntima conexión. "La esperanza no puede existir sin el amor; pues como dice el apóstol Santiago, también los demonios creen y tiemblan, y no obstante, ni esperan ni aman, sino más bien, lo que nosotros por la fe esperamos y amamos, ellos temen que se realice". Es decir, la caridad (el amor) -al igual que la esperanza- es algo que da autenticidad a la fe cristiana. Sin caridad no puede haber auténtica fe: "el Apóstol aprueba y recomienda la fe que obra por la caridad". Y la caridad "no puede existir sin la esperanza". Como resume San Agustín: "ni el amor existe sin la esperanza, ni la esperanza sin el amor, y ninguna de las dos sin la fe".

En definitiva, adorar a Dios para el cristiano es asumir vitalmente la fe, la esperanza y la caridad. Es decir, asumir al Dios trinitario como señor absoluto del universo, que es radicalmente bueno y amoroso, en quien hay que confiar esperanzadamente. Tener fe es tener esperanza y obrar el amor (la caridad). El auténtico amor y la auténtica esperanza sólo brotan de una fe también auténtica. El fundamento de ellas es el Dios trinitario, en quien hay que creer, a quien hay que esperar y a quien se tiene que amar: "Dios debe ser adorado por la fe, la esperanza y la caridad" (San Agustín).

\section{La eclesiología de San Agustín}

San Agustín ha incidido profundamente en el desarrollo y configuración de la eclesiología occidental. Su influjo —debido en buena parte a su 
obra La Ciudad de Dios (De civitate Dei) - no se agota, por lo demás, en la tradición católica, sino que llega hasta la génesis de la tradición protestante, que en la eclesiología de Martín Lutero asume - y radicaliza_ algunas de las tesis más importantes de San Agustín. Esto hace del Obispo de Hipona un autor interesante y clave para entender muchos de los problemas en los que se ha debatido - y se debate - la eclesiología occidental.

\subsection{Iglesia visible e Iglesia invisible}

La eclesiología de San Agustín está centrada en el problema de las relaciones entre Iglesia visible e Iglesia invisible. Ciertamente, no se trata de dos Iglesias, sino de una sola Iglesia articulada por dos dimensiones fundamentales: la dimensión terrena y la dimensión divina. Pero ambas dimensiones forman una sola realidad, es decir, una única Iglesia. Esto es así porque la Iglesia es expresión del "Cristo total" (R. Velasco): "Cristo y la Iglesia no son más que una sóla cosa, un sólo hombre, una sóla persona, un sólo Cristo, el Cristo total, cabeza y miembros". Más aún, el Cuerpo de Cristo es la Iglesia, no sólo la "que está aquí, sino la que está aquí y la extendida por toda la tierra. Y no sólo la Iglesia que vive ahora, sino desde Abel a los que nacerán hasta el fin del mundo y que creerán en Cristo, todo el Pueblo de santos que no forma más que una ciudad. Esta ciudad es el Cuerpo de Cristo... Y Cristo es esto: el Cristo total y universal, unido a la Iglesia".

En este sentido, para San Agustín el Cristo total es el fundamento de la Iglesia: es el "sujeto de la actividad eclesial", así como "de toda la santidad de la Iglesia". Más aún, el Cristo total es el fundamento de la "unidad eclesial": "una unidad que consiste primariamente en vivir en comunión de caridad con todos los hombres, con el Cuerpo de Cristo extendido por toda la tierra". Cristo es, en la visión de San Agustín, lo determinante en la Iglesia: "ni la unidad de la jerarquía, ni la unidad extema de la Iglesia importan por sí mismas, sino en orden a que en la Iglesia no haya más que Cristo, ni haya menos que Cristo: Cristo actualizándose en forma de totalidad”.

Aquí ya se nos está anunciando el motivo central de la eclesiología agustiniana. En efecto, si Cristo constituye la dimensión más esencial de la Iglesia —es decir, su realidad más profunda y última - la Iglesia no puede sino pertenecer, en lo que de más suyo es, a un orden distinto del terreno: la Iglesia no puede pertenecer sino al "'mundo inteligible', al mundo de las realidades esenciales" (R. Velasco). La Iglesia, así entendida, no es más que la civititas Dei, es decir, la Ciudad de Dios. En esencia, la Iglesia es una comunidad de santos, una communio sanctorum. Esta comunidad de santos constituye la dimensión invisible de la Iglesia; es ella la que hace de la Iglesia una Ciudad de Dios ya presente aquí en la tierra. 
Esta comunidad de santos - la Ciudad de Dios presente aquí y ahora“está constituida por quienes han optado amar a Dios hasta el desprecio de sí. Pero esta opción no es primariamente obra de la criatura, sino acción de Dios en ella, obra del Espíritu Santo que, en virtud de su 'caridad' difundi$\mathrm{da}$, realiza ese misterio de 'unidad' que es la 'communio societasquae sanctorum'. Esta 'sociedad de los santos' es la Ciudad de Dios, constituida por esa comunión de ángeles y hombres creada por el Espíritu, y que es la Jerusálén celeste, la Iglesia en su réalidad definitiva".

Si la Iglesia invisible — la Ciudad de Dios- está constituida por quienes han optado amar hasta las últimas consecuencias a Dios, la Iglesia visible - la Ciudad terrena- está constituida por quienes se aman a sí mismos hasta despreciar a Dios. "Dos amores fundaron dos ciudades: el amor propio hasta el desprecio de Dios, la terrena; el amor de Dios hasta el desprecio de sí, la celestial. La primera se gloria de sí misma; la segunda en Dios. Aquélla busca su gloria en los hombres, y ésta tiene su mayor gloria en Dios, testigo de la conciencia". Sin embargo, ambas ciudades no están desconectadas: la Ciudad terrena es la exterioridad de la Ciudad de Dios. Es decir, la Civitas Dei no se identifica con la Iglesia (terrena) pero tampoco existe sin referencia a ella.

Pero, por otra parte, como Ciudad de Dios la Iglesia es una realidad no realizada a plenitud. Realizarse como Ciudad de Dios es la meta escatológica de la Iglesia. Para alcanzar esa meta futura tiene que liberarse de las ataduras "terrenas" y "sensibles" a las que se halla ligada en el momento presente. Estas ataduras terrenas no son otras que las que impone la realidad concreta e histórica. Ahora bien, la Ciudad de Dios no está fuera de la Iglesia terrena, sino que está en ella, dinamizándola y haciendo presente la fuerza del Espíritu que empuja hacia el futuro. Este camino del presente al futuro - de la Iglesia terrena a la Ciudad de Dios- se realiza en un "peregrinar". La Iglesia terrena es el conjunto de peregrinos de la Ciudad de Dios sobre la tierra.

\subsection{El 'peregrinar' de la Iglesia}

Ya lo señalamos, para San Agustín, Iglesia, como comunidad de santos no es, en el aquí y ahora, una realidad plenamente realizada. La Ciudad de Dios es algo ya presente, pero es algo sólo alcanzable definitivamente al final de los tiempos. La Iglesia vive la tensión del "ya, pero todavía no" paulino. Este "ya, pero todavía no" le exige hacer un recorrido: el camino que habrá de recorrer la comunidad de creyentes va de la Iglesia terrestre hacia la Iglesia celeste.

La Iglesia celeste - la Ciudad de Dios plenamente realizada- constituye el origen y meta de la Iglesia terrestre. "Por eso la Iglesia terrestre es 
esencialmente 'peregrina', y su sentido concreto sólo es cognoscible a la luz de la Iglesia celeste". Esta Iglesia celeste es el término último al que apunta la salvación colectiva de la humanidad. Alcanzar esa meta (ya dada desde el principio), recorrer el camino que conduce hasta ella: he aquí el desafío escatológico que el cristianismo plantea a los seres humanos.

Por ser una realidad escatológica, la Iglesia celeste es una realidad que sólo podrá ser alcanzada al final de los tiempos. "Sólo cuando el Cristo total llegue a su entero cumplimiento, llegará también cada miembro de su Cuerpo a su total explosión en Él". Sólo en este momento cobrará plena realidad la "societas sanctorum", la "Ciudad santa", la "Jerusalén de arriba", la "patria de los santos", "donde será para todos y para siempre 'Deus vita communis'".

Ahora bien, los miembros de la Iglesia terrena, es decir, de la Iglesia peregrinante, ya participan de la Iglesia celeste. Más aún, "no son ciudadanos de otra Ciudad que la celeste, como sí la Iglesia de aquí abajo pudiera tener consistencia y definirse por sí misma, al margen de la Jerusalén de arriba. No hay en realidad más Iglesia que la de arriba, y la Iglesia terrestre lo es en cuanto 'peregrina', es decir, en cuanto que su verdadera ciudadanía está en los cielos". En otras palabras, la Iglesia terrena tiene que peregrinar para acceder a su propia identidad. Es la medida en que es peregrina, se acerca más a su verdadera ciudadanía. Pero esa ciudadanía celestial no está fuera de ella, sino que está en ella dinamizándola y conduciéndola hacia su meta. Dicho de otra forma, el peregrinar de la Iglesia terrena es el peregrinar de la Iglesia celeste —en definitiva es ésta la que peregrina-, despojándose de las ataduras terrenales y liberando su realidad celestial más profunda.

"Esto es lo propio de la Iglesia peregrinante: no ser la Iglesia en su realidad verdadera, sino la Iglesia en marcha hacia su realidad verdadera. Una marcha en que la opción del hombre de amar a Dios hasta el desprecio de sí pasa por las más diversas vicisitudes. No sólo esto, sino que, instalado en el amor de sí hasta el desprecio de Dios, ha sido necesaria la acción de Dios en Cristo para cambiar de signo su opción fundamental". Una vez que el ser humano, instalado en el amor a Dios por el sacrificio de Cristo, se pone en camino (viviendo en una comunidad eclesial) hacia la salvación definitiva, el horizonte de ese peregrinaje no puede ser otro que el de la realidad celestial.

Alcanzar esta realidad celestial es la meta del peregrinaje, pero se trata de una meta ya presente en el origen. El recorrido lo realiza la misma Iglesia celestial. Por consiguiente, su naturaleza es esencialmente divina, no humana. "Porque la Ciudad de los santos trae su origen de arriba, aunque engendra aquí ciudadanos, en los que peregrina hasta que llegue el 
tiempo de su reinado". "En la medida en que realmente los miembros de la Iglesia peregrinante son 'ciudadanos' de la Ciudad celeste, la Iglesia en su estadio terreno es también una communio sanctorum, la comunidad de los santos".

\section{A modo de conclusión}

No cabe ninguna duda que desde hace bastante tiempo el pensamiento teológico de San Agustín ha sido superado críticamente -es decir, en la forma hegeliana de superación/conservación- por teologías que han asumido supuestos antropológicos y filosóficos cualitativamente distintos a los asumidos por el Obispo de Hipona. En esto no se puede ser anacrónico, pensando que con San Agustín se puede dar respuesta a los ingentes problemas que tiene planteados el hombre actual. Es más que evidente que el dualismo antropológico de tipo neoplatónico (del que San Agustín nunca logró escapar) es insuficiente para dar cuenta de lo que es la realidad humana en tanto que realidad estructural.

Este dualismo se hace presente en la concepción que San Agustín tiene de la voluntad salvífica de Dios respecto del hombre. Aunque nuestro autor sostiene que la salvación compete al hombre total -en cuerpo y alma, el acento está puesto en lo que es propiamente humano: el alma, que es la que permite al ser humano alcanzar la "plenitud y perfección de la caridad, que es la única que causa la unión y la semejanza con Dios" (San Agustín). Asimismo, la eclesiología agustiniana está montada sobre esquemas dualistas. Aunque defienda la tesis de una Iglesia mixta (Ecclesia mixta), la unidad entre Iglesia terrena e Iglesia celeste es una unidad que no logra articular suficientemente ambas realidades. Lo terreno sigue siendo $-\mathrm{y}$ seguirá siendo- lo no real, es decir, lo degradado, lo negativo, lo que encarcela a la verdadera realidad, que es la realidad celestial. Estamos ante un esquema platónico con todas sus consecuencias y limitaciones.

Asumir sin reparos $\longrightarrow$ en bloque - el pensamiento de San Agustín implicaría asumir estas limitaciones. Pero, en todo caso, no sería un problema de San Agustín, sino de los que asumen acríticamente su pensamiento. Estos serían insensibles a la nueva realidad histórica y cultural del cristianismo actual. Además tendrían opciones culturales (filosóficas y científicas) que el Obispo de Hipona no tuvo y no podía tener. Y San Agustín les daría una enseñanza fundamental: les enseñaría que el cristianismo tiene que dialogar con la cultura de su época. En este punto, el Obispo de Hipona fue un teólogo que estuvo a la altura de su tiempo. Entró en confrontación con las corrientes culturales y religiosas más importantes de su momento e introdujo en la teología cristiana nociones y categorías del pensamiento filosófico más elaborado de la época. 
Por otra parte, hay aportes del pensamiento de San Agustín que en cierto modo se pueden estimar permanentes y actuales. Entre otros, se pueden apuntar los siguientes: a) su concepción de la Iglesia como una realidad peregrina. Esta concepción —asumida en su momento por el Concilio Vaticano II- se convierte en una instancia crítica de la misma Iglesia, sobre todo de aquellas autocomprensiones de la misma que la ven como una realidad ya plenamente realizada, es decir, como el Reino de Dios aquí en la tierra; y b) su idea de la caridad como virtud teologal fundamental. Sin ella — nos dice San Agustín - no puede haber una auténtica fe en el Dios de Jesucristo.

San Agustín — si no se estudia dogmáticamente su pensamiento y si ese estudio no se hace con fines puramente apologéticos- puede decir mucho al pensamiento teológico de nuestro tiempo. No cabe duda que fue un pensador de gran vitalidad y creatividad, que se tomó en serio el desafío que representa el misterio de Dios para la inteligencia humana. Este desafío lo tenemos planteado también nosotros. Debemos enfrentarlo con vitalidad y creatividad, abiertos siempre a los desafíos que plantea la realidad actual.

Ciudad de México, 1993-San Salvador, 1996

\section{Notas}

1. Trapć, A., San Agustin. En Quastcn, J., Patrologia. Madrid, BAC, 1978. p. 405

2. Sicrra Bravo, R., Doctrina social y económica de los Padres de la Iglesia. Madrid, COMPI, 1967. p. 740

3. A. Trapé ofrece una visión bastante cxhaustiva de las obras de San Agustín (libros, cartas y tratados), de sus cdiciones, de sus traducciones (al alcmán, cspañol, francés c italiano) y de los artículos y/o libros más importantes que sobre ellas sc han cscrito. Cfr. Trapé, A., Ob. Cit., pp. 420-481

4. Una muestra de los cientos - y quizás miles - de páginas que sc han cscrito sobrc la vida y obra de San Agustín se encuentra en el trabajo de A. Trapé, ya citado.

5. Ib. p 419

6. Ib.

7. También se enfrentó contra los priscilianistas, marcionistas y judios, así como contra divcrsas herejías. Cfr. Trapć, A., Ob. Cit., pp. 468-470

8. Pricto, T., "Introducción" a De las costumbres de la Iglesia católica y de los maniqueos. Madrid, BAC, 1975. p. 208. T. IV

9. lb.

10. San Agustín, Ob. Cit., p. 231

11. Ib. p. 215

12. Prieto, T., Ob. Cit., p. 217

13. Ib.

14. Ib.

15. Ib. 
16. Ib.

17. Ib.

18. Ib.

19. Ib. p. 219

20. Ib.

21. Ib.

22. San Agustín, Ob. Cit. p. 235

23. Ib. p. 236

24. Ib. p. 237

25. Ib. pp. $242-243$

26. Ib. pp. 244-245

27. San Agustín, Enquiridión o manual de la fe, de la esperanza y de la caridad. Madrid, BAC, 1975. p. 411 y ss.

28. lb. p. 245

29. Ib. p. 252

30. Ib. p. 255

31. lb.

32. Ib.

33. Ib. p. 260

34. Congar, Y., Eclesiología. Desde San Agustín hasta nuestros dias. Madrid, BAC, 1963. p. 2

35. Ib. p. 4

36. Ib.

37. Santamarta, S., «Introducción» a De la unidad de la Iglesia. Madrid, BAC, 1975. p. 550, Vol. IV

38. San Agustín, Ob. Cit., nota 35, p. 553

39. Ib. p. 606

40. Ib. p. 606

41. Ib. p. 612

42. Congar, Y., Ob. Cit., p. 4

43. Ib. p. 612

44. Congar, Ob. Cit., p. 4

45. San Agustín, Ob. Cit., p. 612

46. P. Roussclot, J. Huby, Christus. La religión chrétienne. En Capánaga, V., "Introducción gencral” a los Tratados sobre la gracia de San Agustín. Madrid, BAC, 1949. p. 27

47. Capánaga, V., Ob. Cit., p. 27

48. Ib. p. 28 y ss

49. Ib.

50. Ib.

51. Ib.

52. Ib. p. 29

53. Ib. p. 27

54. Ib. p. 29

55. San Agustín, De la naturaleza y de la gracia. Madrid, BAC, 1949. p. 885

56. Capánaga, V., "Introducción" a De la naturaleza y de la gracia. Ed. cit., p. 810 57. Ib. 
58. Ib.

59. San Agustín, Enquiridión, Ed. cit., p. 400

60. Ib. pp. $400-401$

61. Ib.

62. Ib. p. 402

63. Ib.

64. Ib.

65. Cfr. Moltmann, J., Teología de la esperanza. Salamanca, Sígueme, 1972

66. Ib. p. 405

67. Ib.

68. Ib.

69. Cfr. Sobrino, J., "Teología en un mundo sufriente. La teología de la liberación como 'Intellectus Amoris'". RLT, V(15):243-266

70. San Agustín, Sobre la epístola de San Juan a los Partos. En Sierra Bravo, R., Ob. Cit., p. 780

71. Ib.

72. Ib. p. 781

73. Ib.

74. Ib.

75. Ib. pp. $406-407$

76. Ib.

77. Ib. p. 407 (subrayado nuestro)

78. Velasco, R., La eclesiologia en la historia. Valencia, EDICEP, 1976. p. 118

79. San Agustín (P.L. XXXVII), citado por R. Velasco, Ob. Cit. p. 118

80. Ib. p. 120

81. Ib. p. 121

82. Ib.

83. Velasco, R., Ob. cit., p. 124

84. San Agustín, La Ciudad de Dios. Citado por R. Sicrra Bravo, Ob. Cit. p. 852

85. Ib. p. 122

86. Ib.

87. Ib. p. 123

88. Ib.

89. Ib. p. 125

90. Cfr. San Agustín, La Ciudad de Dios. En R. Sicrra Bravo, Ob. Cit., pp. 858-859

91. Ib. p. 124

92. San Agustín, La Ciudad de Dios. Citado por R. Velasco. Ob. Cit., p. 125

93. Velasco, R., Ob. Cit., p. 125 